\title{
QPX (Quahaug Parasite X), a pathogen of northern quahaug Mercenaria mercenaria from the Gulf of St. Lawrence, Canada
}

\author{
S. K. Whyte ${ }^{1}$, R. J. Cawthorn ${ }^{1}$, S. E. McGladdery ${ }^{2}$ \\ ${ }^{1}$ Department of Pathology and Microbiology, Atlantic Veterinary College, University of Prince Edward Island, \\ 550 University Avenue, Charlottetown, Prince Edward Island, Canada C1A 4P3 \\ ${ }^{2}$ Department of Fisheries and Oceans, PO Box 5030, Moncton, New Brunswick, Canada E1C 9B6
}

\begin{abstract}
In 1989, an unidentified protistan parasite, QPX (Quahaug Parasite X), was found in quahaugs Mercenaria mercenaria (Linnaeus, 1758) from a hatchery on Prince Edward Island, Canada, which was suffering extensive mortalities. The parasite was identical to one reported from mass mortalities of wild populations of quahaugs in the late 1960's. QPX elicits a massive inflammatory response characterized by extensive infiltration of haemocytes with necrosis of the connective tissues in the digestive gland and within the musculature of the foot. Light microscopy revealed a range of parasite stages including thick-walled cyst-like stages. The majority of QPX tissue stages were enclosed within a translucent 'halo' indicative of possible host tissue lysis. The same feature was observed in QPX isolated from quahaug tissue cultured on potato dextrose agar. Culture in sterile artificial seawater and on potato dextrose agar resulted in production of a biflagellate stage. Features of all developmental stages observed are described and compared with those of the Thraustochytriales and Labyrinthulales.
\end{abstract}

KEY WORDS: Quahaug $\cdot$ QPX · Thraustochytriales - Labyrinthulales · Histopathology

\section{INTRODUCTION}

Since 1989, a shellfish hatchery on Prince Edward Island (PEI), Canada, has suffered significant mortalities among juvenile and adult quahaugs (= hard clams) Mercenaria mercenaria. The connective tissue and muscle of moribund quahaugs were found to be infected with an invasive eukaryotic organism. This organism is identical to one reported by Drinnan \& Henderson (1963) in a limited population of quahaugs in New Brunswick and subsequently from the same hatchery on PEI during the late 1960's. The organism has yet to be conclusively identified and in this paper is referred to as QPX (Quahaug Parasite X). The various stages of the parasite observed to date are described in detail along with the pathological changes observed in quahaugs infected with QPX and the in vitro development and culture characteristics of isolated parasitic stages from infected tissues.

\section{MATERIALS AND METHODS}

Laboratory maintenance of quahaugs. Infected quahaugs (shell height 15 to $30 \mathrm{~mm}$ ) were collected from a hatchery on PEI and transferred to the Aquatic Animal Quarantine Facility of the Atlantic Veterinary College, University of PEI. Quahaugs were maintained in a closed-circulation, artificial saltwater (Instant Ocean ${ }^{\circledR}$ ), quarantine system. Water temperatures were maintained at 22 to $25^{\circ} \mathrm{C}$ and salinities of 28 to $30 \%$. Quahaugs were fed daily with cultured algae (Chaetoceros gracilis and Tahitian isochrysis). Tissue samples (digestive gland, rectum, mantle, gill and kidney) were extracted and processed for histological examination (Howard \& Smith 1983).

Light microscopy. Transverse sections of the entire quahaug were cut and fixed in Davidson's solution for $24 \mathrm{~h}$ followed by paraffin-infiltration and embedding (Howard \& Smith 1983). Sections 5 to $7 \mu \mathrm{m}$ thick were 
stained with Harris' modified haematoxylin and $0.5 \%$ alcoholic eosin y (McGladdery et al. 1991). Additional slides were prepared from the same samples using Periodic Acid Schiff (PAS) reagent and Gomori Methenamine Silver (GMS) stain. Counter stains were used for both PAS and GMS.

Transmission electron microscopy. Isolated parasite stages and tissue samples (digestive gland, rectum, mantle, gill and kidney) were collected and fixed in $3 \%$ gluteraldehyde in $0.1 \mathrm{M}$ sodium cacodylate buffer, pH 7.8 , for 24 h at $4^{\circ} \mathrm{C}$. Fixed tissue was washed for $2 \mathrm{~h}$ at $4^{\circ} \mathrm{C}$ in the same buffer and tissue samples cut into $1 \mathrm{~mm}^{3}$ pieces. Material was post-fixed in buffered $2 \%$ $\mathrm{OsO}_{4}$ for $2 \mathrm{~h}$ at the same temperature, dehydrated through a series of ethanols and embedded in Epon. Sections (90 nm thickness) were cut and stained with $5 \%$ uranyl acetate for $30 \mathrm{~min}$, lead citrate for $2 \mathrm{~min}$, and observed with a Hitachi 7000 operated at $75 \mathrm{kV}$.

Isolation of the parasite from quahaug tissue. The entire quahaug, exclusive of the foot, was washed 2 to 3 times in sterile artificial seawater (SAS) (28 to $30 \% \mathrm{~S}$ ) plus $200 \mathrm{IU}$ penicillin $\mathrm{ml}^{-1}$ (Gibco), $200 \mu \mathrm{g}$ streptomycin $\mathrm{ml}^{-1}$ (Gibco) and $0.50 \mu \mathrm{g}$ fungizone ${ }^{\circledR} \mathrm{ml}^{-1}$ (Gibco) placed in a $7 \mathrm{ml}$ glass tissue grinder (Sigma) and macerated in $1 \mathrm{ml}$ of SAS plus antibiotics. The resulting homogenate was washed into a $9 \mathrm{~cm}$ diameter petri dish with SAS plus antibiotics and maintained at $26^{\circ} \mathrm{C}$ in the dark After $8 \mathrm{~h}$ the supernatant was decanted and clean SAS plus antibiotics added. Petri dishes were returned to the incubator and checked daily for parasite development.

Culture in fluid thioglycollate medium (FTM). Tissues containing 'QPX' were also incubated in fluid thioglycollate medium, following the technique described by Ray (1966) for diagnosis of Perkinsus marinus in oysters. Quahaug tissue (digestive gland, rectum, mantle and gill) was excised, washed 2 to 3 times in SAS and cultured in FTM (Difco) containing chloramphenicol (Sigma) $\left(0.1 \mathrm{~g} 10 \mathrm{ml}^{-1}\right)$ and nystatin (Sigma) (40000 usp units $10 \mathrm{ml}^{-1}$ ). After $5 \mathrm{~d}$ at room temperature $\left(20 \pm 2^{\circ} \mathrm{C}\right)$ a sample was removed, stained with a $50 \%$ Lugol's iodine solution and examined microscopically for the presence of the parasite. The tissue sample was subsequently washed with SAS (28 to $30 \%$ S) plus antibiotics, cut into $0.5 \mathrm{~cm}^{2}$ pieces and placed into a $9 \mathrm{~cm}$ diameter petri dish. This was main- tained in the dark at $26^{\circ} \mathrm{C}$ and checked daily for development of the parasite.

Culture in minimum essential medium (MEM). The parasite was isolated from quahaug tissue as described above and the homogenate transferred to a centrifuge tube and processed according to Bower (1987a). The parasite was incubated in the dark at $26^{\circ} \mathrm{C}$ and checked daily for parasite development

Culture on potato dextrose agar (PDA). The digestive gland, gill and mantle were removed from the quahaug, washed in SAS and macerated in a sterile mortar and pestle with SAS. The resulting homogenate was added to petri dishes containing PDA and held at $14{ }^{\circ} \mathrm{C}$ for 3 to $8 \mathrm{~d}$. Samples of the colonies which grew were stained with Giemsa and examined with phase contrast and bright field microscopy.

\section{RESULTS}

\section{Histopathology}

The parasite was consistently found in connective tissue and muscle of the quahaug where it elicited a significant inflammatory response as characterized by massive haemocyte infiltration and necrosis of the affected area (Fig. 1). There was no evidence of complete phagocytosis or encapsulation of QPX by haemocytes despite the massive infiltration of haemocytes. There did, however, appear to be some attempt by the host to encapsulate some stages of the parasite although parasite proliferation did not appear to be affected by the tissue response. Often the parasites were surrounded by a clear, cell-free region or 'halo' with an adjacent haemocytic inflammation (Fig. 2). Halos measured up to double the diameter of the parasites and, in heavily infected areas, halos appeared to coalesce (Fig. 3). In some specimens, however, haemocytes were observed within the halo, lying around the parasite wall (Fig. 4). In tissue sections where the halos were not evident, the parasite was completely surrounded by host haemocytes (Fig. 5) but not encapsulated by them. The thick cell wall which encompassed some stages of QPX stained positive with PAS and GMS stains although the parasite itself did not (Fig, 6).

Figs. 1 to 7. QPX infecting Mercenaria mercenaria. Fig. 1. Quahaug parasite (Q) in connective tissue of the digestive gland resulting in a massive haemocytic inflammatory response $\left(\mathrm{H} \& \mathrm{E}_{\text {; }}\right.$ scale bar $\left.=44 \mu \mathrm{m}\right)$. Fig. 2 . Quahaug parasite in connective tissue of mantle surrounded by a cell-free region (CR) $\left(H \& E_{\text {i }}\right.$ scale bar $\left.=28 \mu \mathrm{m}\right)$. Fig. 3. Quahaug parasites each surrounded by individual cell-free regions which have coalesced $\left(H \& E_{\text {; scale bar }}=40 \mu \mathrm{m}\right)$. Fig. 4. Quahaug parasite surrounded by a cell-free region which has been breached by host haemocytes $(H)\left(H \& E_{i}\right.$ scale bar $\left.=30 \mu \mathrm{m}\right)$. Fig. 5 , Quahaug parasite surrounded by host haemocytes (H\&E; scale bar $=27 \mu \mathrm{m})$. Fig. 6. Quahaug parasite in connective tissue of digestive gland. Parasite cell wall (CW) is visible (GMS; scale bar $=37 \mu \mathrm{m}$ ). Fig. 7. (a) Quahaug parasite containing translucent globules (H\&E; scale bar $=35 \mu \mathrm{m})$. (b) Electron micrograph of a multinucleate stage of the quahaug parasite located within muscle tissue $(\times 3150)$. N: nucleus 
W

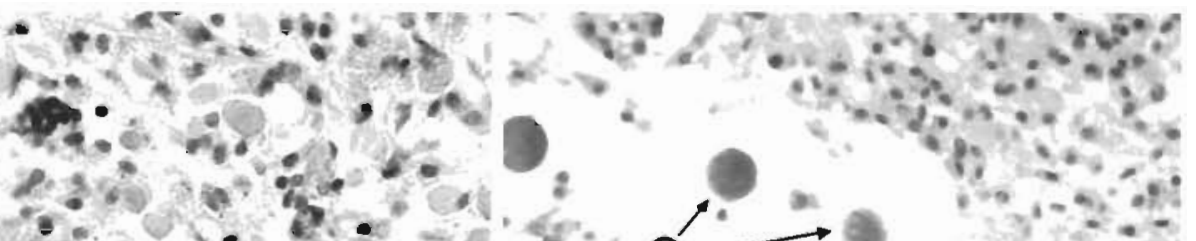

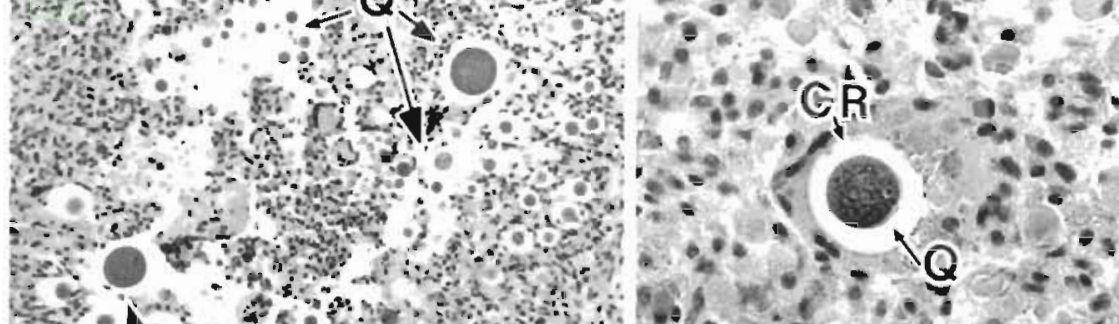

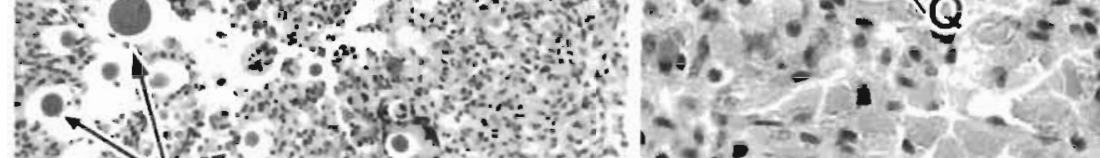

a

1

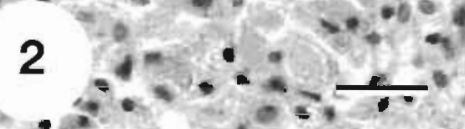

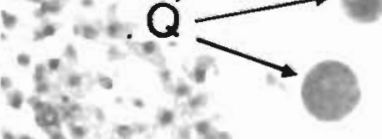

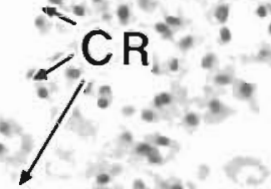

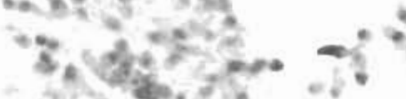

(a) an

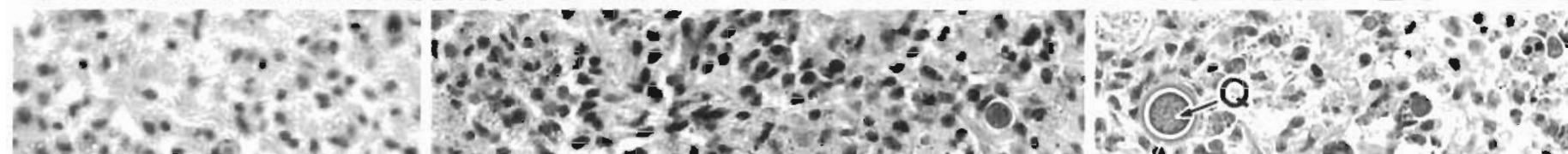

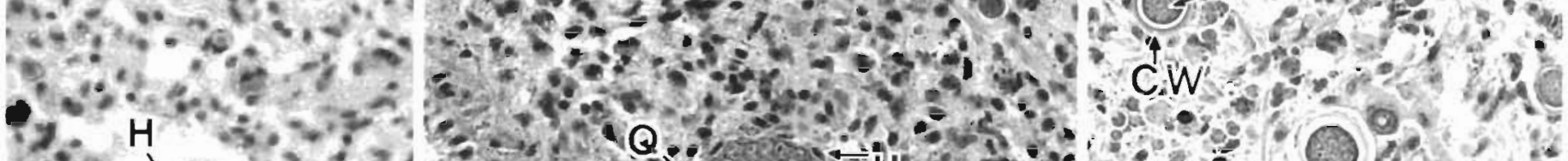

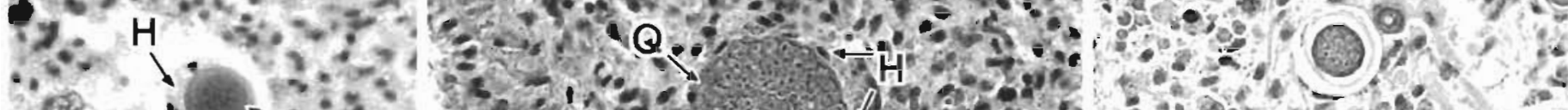

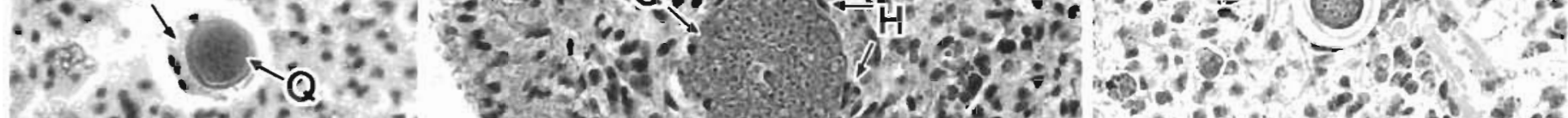

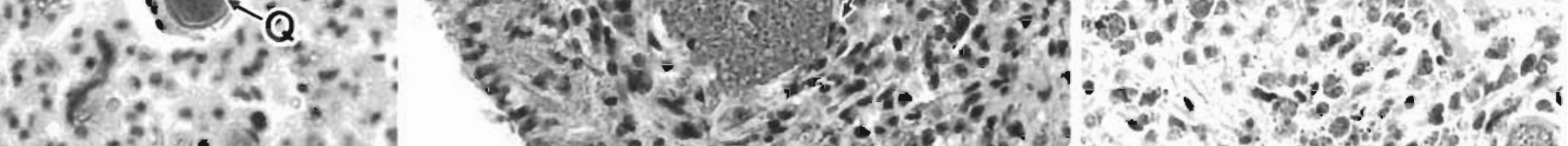

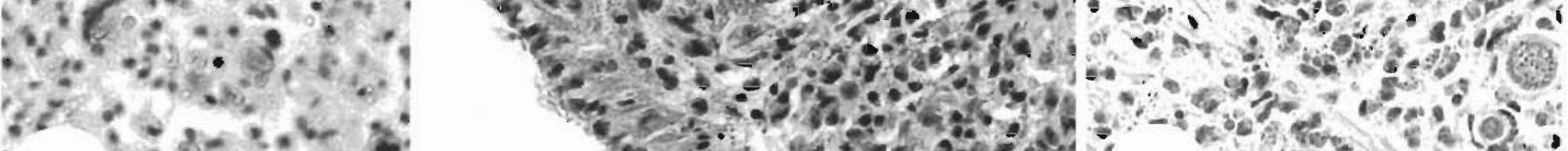

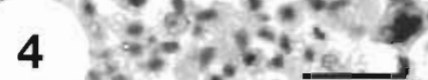

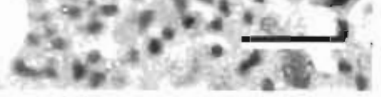

5

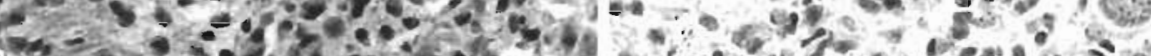

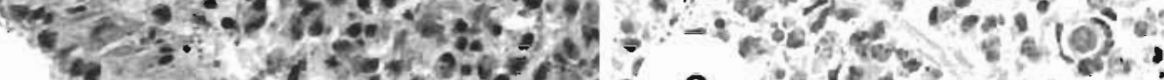

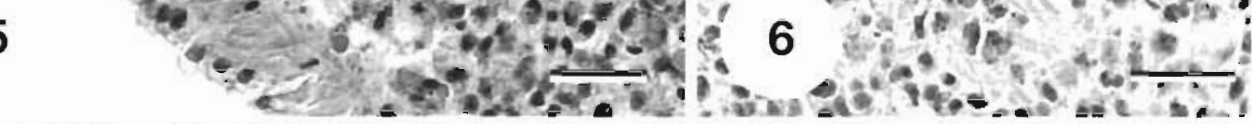

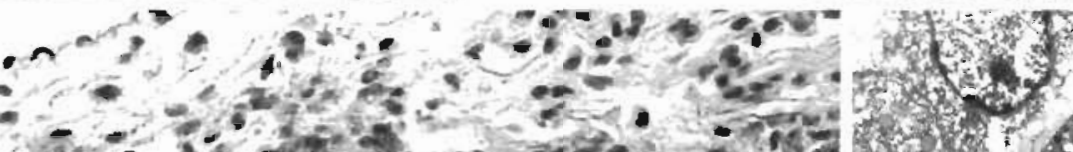

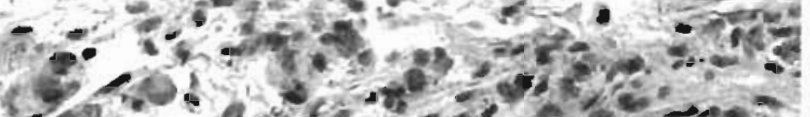

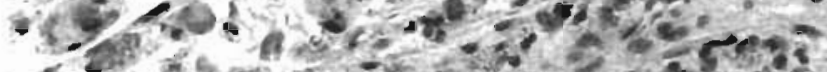

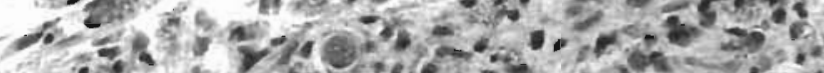

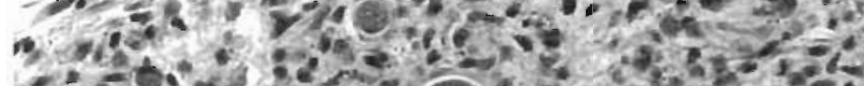
C.

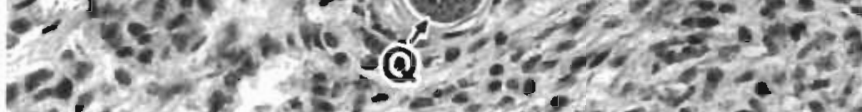

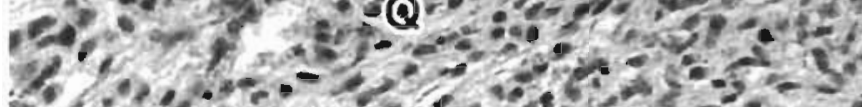

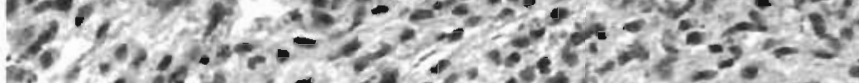

$7 a$ s

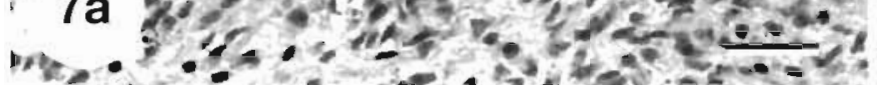

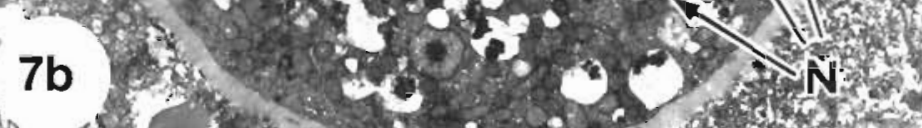
W.

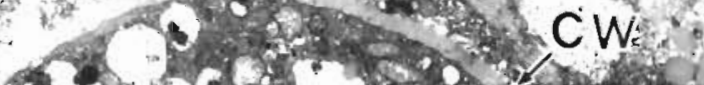
1.2.

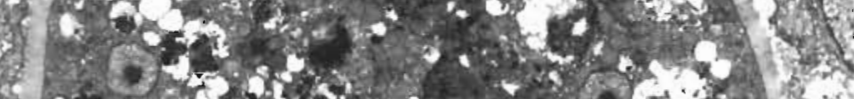

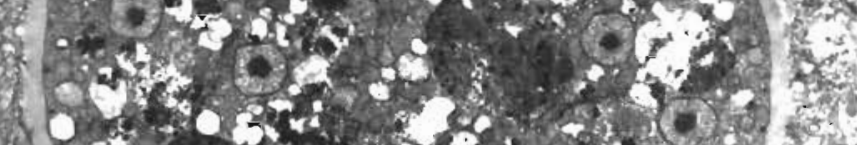
ostorit 1). . 12

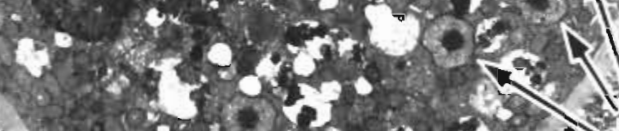


Parasites were spherical and ranged in diameter from 5 to $71 \mu \mathrm{m}$. Ultrastructurally both uninucleate and multinucleate stages were observed in the tissues although it was not possible, histologically, to determine at what size the parasite was uninucleate or when the transition to the multinucleate stage occurred. Parasite stages greater than $30 \mu \mathrm{m}$ in diameter often contained translucent globules (Fig. 7a) and many stages appeared to be multinucleate (Fig. $7 \mathrm{~b}$ ). In some instances, numerous daughter cells, 5 to $7 \mu \mathrm{m}$ in diameter, were observed dissociating from one another (Fig. 8a); these smaller stages were uninucleate (Fig. 8b).

\section{Culture in SAS}

Vegetative stages of QPX, ranging from 8 to $71 \mu \mathrm{m}$ in diameter, increased in size during $5 \mathrm{~d}$ incubation in SAS at $26^{\circ} \mathrm{C}$. It was difficult to determine at the light microscope level whether cell division was occurring (Fig. 9a), although ultrastructurally karyokinesis was observed as indicated by the presence of multinucleate stages (Fig. 9b). In some cases QPX appeared to have undergone bipartitioning of the cell by cytokinesis resulting in a morula-like cluster of daughter cells contained within the cell wall of the original parasite (Fig. 9c). Cell division continued over Days 2 and 3 and the newly formed daughter cells increased in size but remained closely associated within the cell wall (Fig. 10a). The cell wall of the original parasite was not easily discerned at the light microscope level but could be identified at the ultrastructural level (Fig. 10b). By Day 4 the ball of cells continued to increase in size and appeared to contain many daughter cells of differing size, some of which were multinucleate (Fig. 11a, b). These daughter cells were contained within the original cell wall despite beginning to dissociate from one another, as evidenced by the increased space between individual cells (Fig. 11b). Some daughter cells, greater than $28 \mu \mathrm{m}$ in diameter, contained numerous uninucleate, biflagellate stages (Fig. 12). On Day 5 of incubation in vitro, daughter cells were observed to be bursting apart and liberating their contents (Fig. 13a, b). Motile, biflagellated, uninucleate stages were observed on Day 5.

\section{Culture in FTM}

Culture of infected tissues in FTM for $5 \mathrm{~d}$ did not result in an increase in size of the parasite, nor did the parasite stain blue/black with Lugol's iodine solution. Biflagellate stages were collected $2 \mathrm{~d}$ after the tissue had been removed from the FTM and placed into SAS. During the period in SAS, no cell division or increase in parasite size was observed.

\section{Culture in MEM}

Culture of the isolated vegetative stages of the parasite for $3 \mathrm{~d}$ in MEM did not result in any increase in parasite size or cell division. Biflagellate stages were produced $70 \mathrm{~h}$ after transfer of the parasite to SAS and incubated at $26^{\circ} \mathrm{C}$. As with FTM no increase in parasite size or cell division was apparent prior to release of motile stages.

\section{Culture on PDA}

Culture of the parasite on PDA resulted in growth of yellowish white colonies 1 to $3 \mathrm{~mm}$ in diameter after 3 to $8 \mathrm{~d}$ at $14^{\circ} \mathrm{C}$. Some of these colonies developed hyphal nets. Smears taken from non-hyphae producing colonies revealed the presence of proliferative spheres ranging in diameter from 10 to $64 \mu \mathrm{m}$ (Fig. 14) with spheres over $25 \mu \mathrm{m}$ containing smaller daughter cells measuring 4 to $5 \mu \mathrm{m}$. The walls of these spheres ranged in thickness from 1 to $8 \mu \mathrm{m}$. Biflagellated stages were apparent after $8 \mathrm{~d}$ in culture.

\section{DISCUSSION}

The parasite, QPX, induces a massive haemocytic infiltration response, and disruption of affected tissue can result in mortalities of up to $100 \%$ in certain stocks. Some haemocytes appeared to attempt encapsulation of the parasite, although no complete parasite encapsulation or degeneration of QPX was observed. The parasite was often surrounded by a cell-free region both in vivo and when cultured on PDA. This phenomenon has also been reported in other protistan organisms, in particular those which belong to the Thraustochytriales and Labyrinthulales (Perkins 1973, Olive 1975), e.g. Labyrinthuloides haliotidis which was identified in abalone Haliotidis sp. (Bower 1987b). It was suggested that extracellular digestion by lytic enzymes released from these parasites could be responsible for the cell-free region (Perkins 1973, Bower 1987b, Bower et al. 1989). Extracellular digestion was not evaluated in this study, although future work may determine the extent of formation of the cell-free region in vitro and whether the regions enlarge during extended culture. Bower (1987b) noted that the space surrounding $L$. haliotidis contained host cell debris and hollow ectoplasmic membrane tubes. In the present study, the space surrounding the majority of quahaug parasites was free of any cell debris, although in some specimens radial extremities of an ectoplasmic net-like structure were present. 


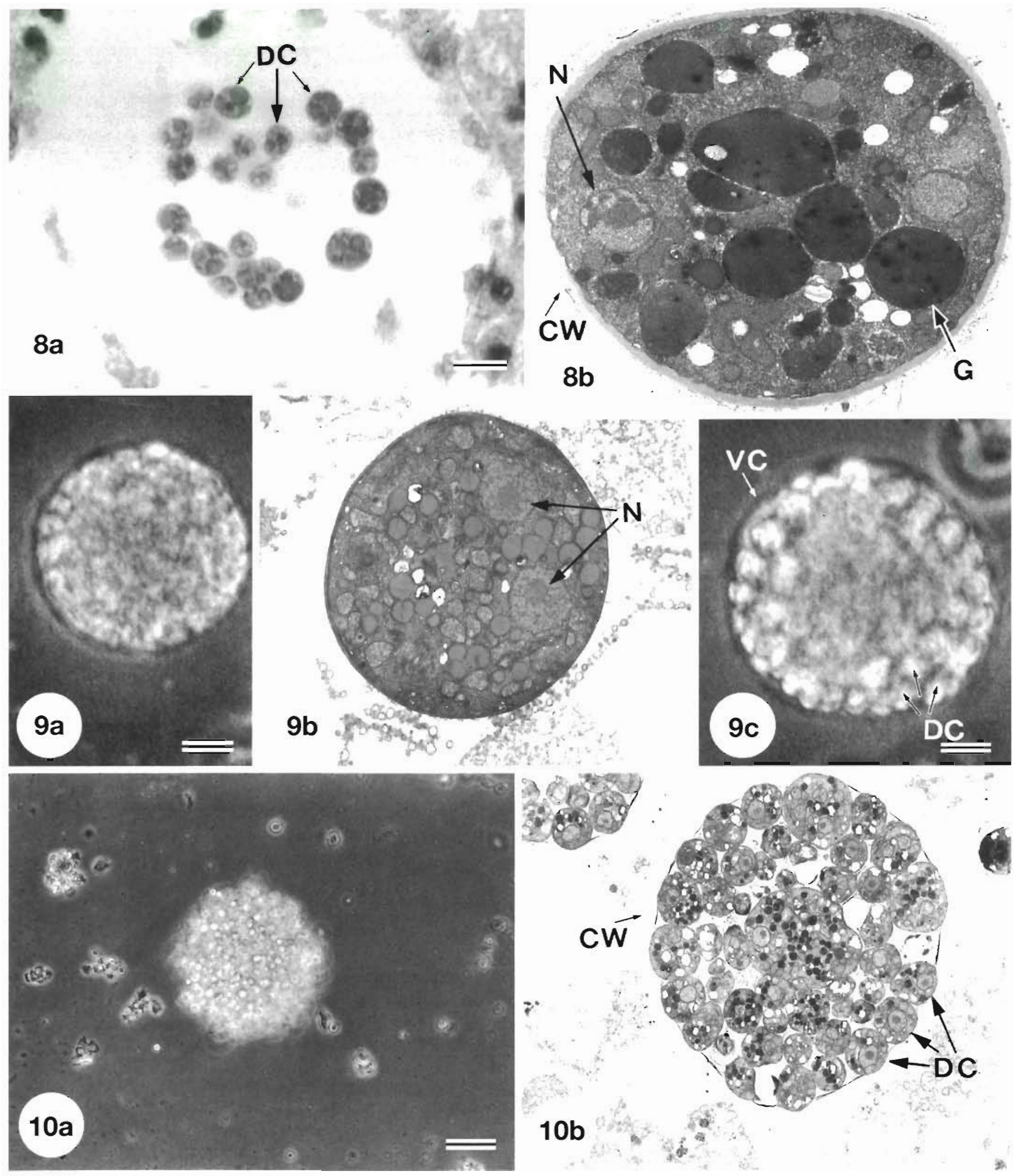

Figs. 8 to 10. QPX infecting Mercenaria mercenaria. Fig. 8. (a) Daughter cells (DC) of the quahaug parasite vegetative stage beginning to dissociate from one another $(\mathrm{H} \& \mathrm{E}$; scale bar $=10 \mu \mathrm{m})$. (b) Electron micrograph of a uninucleate daughter cell $(\times 8100)$. CW: parasite cell wall; G: electron-dense globules; $N$ : nucleus. Fig. 9. Isolated vegetative stages of the quahaug parasite incubated in sterile artificial seawater (SAS) fortified with antibiotics. (a) A vegetative cell in SAS after $1 \mathrm{~d}$ (scale bar $=8 \mu \mathrm{m}$ ). (b) Electron micrograph of a multinucleate vegetative cell after $1 \mathrm{~d}$ in SAS $(\times 1800)$. (c) A vegetative cell (VC) after $2 \mathrm{~d}$ in SAS. Daughter cells are visible within vegetative cell (scale bar $=12 \mu \mathrm{m}$ ). Fig. 10. (a) A ball of cells resulting from a vegetative stage placed into SAS and incubated for $3 \mathrm{~d}$ (scale bar = $61 \mu \mathrm{m}$ ). (b) Electron micrograph showing daughter cells dissociating from one another but remaining within the cell wall of the original vegetative cell $(\times 4000)$ 

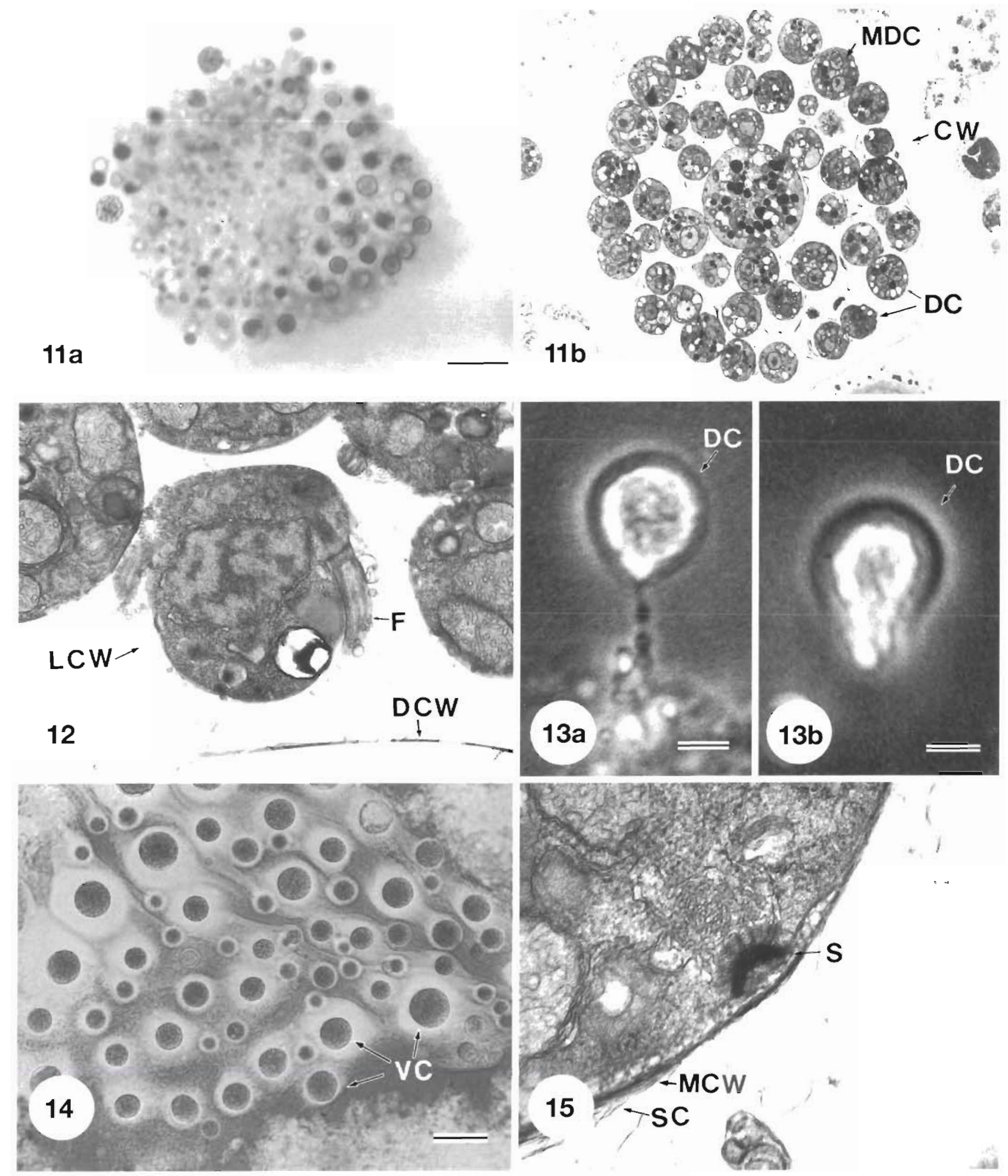

Figs. 11 to 15. QPX infecting Mercenaria mercenaria. Fig. 11. (a) A ball of cells resulting from a vegetative stage placed into SAS and incubated. for $4 \mathrm{~d}$ (scale bar $=79 \mu \mathrm{m}$ ). (b) Electron micrograph demonstrating further dissociation of daughter cells (DC), some of which are multinucleate $(\mathrm{MDC})(\times 1800)$. CW: parasite cell wall. Fig. 12. Electron micrograph of a daughter cell containing uninucleate, biflagellate stages $(\times 1800)$. DCW: daughter cell wall; F: flagellum; LCW: laminated cell wall. Fig. 13. Daughter cells releasing their contents after $5 \mathrm{~d}$ incubation of vegetative cells in SAS (scale bars $=70 \mu \mathrm{m}$ ). Fig. 14. Vegetative cells (VC) produced from quahaug tissue grown on potato dextrose agar $(P D A)$ (scale bar $=41 \mu \mathrm{m}$ ). Fig. 15. Electron micrograph of a sagenogenetosome-like structure (S) in a vegetative cell located

in quahaug connective tissue $(\times \overline{4} 500)$. MCW: multilaminate cell wall; SC; scale-like material of the cell wall 
Both Labyrinthuloides haliotidis and other thraustochytrid and labyrinthulid species possess an organelle, unique to the Thraustochytriales and Laybyrinthulales, termed a sagenogenetosome from which an ectoplasmic net rhizoidal system develops (Alderman et al. 1974, Perkins 1974, Bower 1987b). The ectoplasmic net has been reported to be involved in anchoring cells to the substrate, motility of the cells on the substrate and also the lytic activity of the cells during extracellular digestion (Perkins 1973, Olive 1975, Jones \& O'Dor 1983, Moss 1985). Ectoplasmic net formation was not conclusively identified in QPX during this study, either in vivo or when cultured in MEM, FTM, SAS or on PDA, although a structure similar to the sagenogenetosome was observed in some vegetative cells (Fig. 15). McLean \& Porter (1982) also noted a lack of ectoplasmic net formation in the thraustochytrid parasite from the nudibranch Tritionia diomedea despite the presence of a presumed sagenogenetosome and suggested that the functions of a net were unnecessary for an internal parasite. In contrast Jones \& O'Dor (1983) noted that the ectoplasmic net of the internal thraustochytrid parasite isolated from the gills of the squid Illex illecebrosus was an important feature of the parasite in squid gills, and its effects were clearly demonstrated in the surrounding tissues. Thus the presence of an ectoplasmic net would appear to be better suited for facultative parasitism (Jones \& O'Dor 1983). Development of hyphae from some of the colonies grown on PDA may suggest that the parasite did develop ectoplasmic nets although the possibility that contaminating organisms were present cannot be overlooked, especially considering that a mixture of quahaug tissues had been used to inoculate the plates. Attempts were made to minimize contamination by washing quahaug tissue in SAS prior to culture. Since reinfection of quahaugs with this parasite has not yet been attempted it could be suggested that the organism isolated in vitro was not QPX. It should be noted, however, that QPX was the only organism isolated from infected quahaugs, and infection was confirmed histologically by removing some tissue from the same quahaugs used to isolate QPX in vitro. Despite the absence of the ectoplasmic net, QPX may still have been eliciting some lytic activity since cell-free regions were observed surrounding the parasite both in vivo and when cultured on PDA. There was, however, no ultrastructural evidence of lysed cells as observed in other parasites (Perkins 1973, Jones \& O'Dor 1983, Bower 1987b).

FTM is routinely used for diagnosis of all the known apicomplexan parasites belonging to the apicomplexan family Perkinsidae, as this medium facilitates the enlargement and identification of the prezoosporangial stage following staining with Lugol's iodine solution (Ray 1966). QPX did not increase in size or undergo any development when cultured in FTM for up to $5 \mathrm{~d}$. This finding is consistent with these for Labyrinthuloides haliotidis (Bower 1987b). QPX did, however, produce biflagellate stages after $2 \mathrm{~d}$ in SAS following incubation in FTM. It is uncertain if $L$, haliotidis would produce zoospores if similarly placed into seawater following FTM culture, especially since Bower (1987b) noted that the cells appeared abnormally puckered and thick-walled following incubation in FTM.

The wall of QPX exhibited different properties with regard to uptake of various stains. Neither QPX nor Labyrinthuloides haliotidis (Bower 1987b) stained blue/black with the iodine solution, suggesting the wall of QPX may be impermeable to the iodine solution. The wall of QPX was, however, PAS positive although the parasite itself was not. In addition the wall of QPX was prominently GMS positive; the GMS stain is used routinely as a diagnostic stain for fungal agents (Hay 1989).

There was a variation in the thickness of the cell walls in different specimens of QPX. In some specimens, the cell wall appeared to consist of fibrous material (Figs. $7 \mathrm{~b} \& 8 \mathrm{~b}$ ) similar to that described for some labyrinthulid spp. and most thraustochytrid spp. (Perkins 1974). In other specimens, the wall consisted of a loose multilaminar structure (Fig, 15), which was comparable with that of Labyrinthuloides haliotis (Bower 1987b), other labyrinthulid spp. and a few thraustochytrid spp. (Perkins 1974, Moss 1985). Differences in the appearance of the cell wall of labyrinthulid spp. may be a consequence of environmental conditions, whereas the walls of most thraustochytrid spp. are never obviously laminated regardless of the substrate on which they grow (Perkins 1974). Different developmental stages of these parasites may also account for differences in cell wall appearance (Moss 1985).

QPX did not require a nutritionally complex culture medium to enable development from the vegetative stage to the motile form of the parasite. Placing vegetative stages directly into SAS resulted in enlargement of the parasite with successive karyokinesis and bipartitioning of the cell, to ultimately release biflagellate stages after $5 \mathrm{~d}$ at $26^{\circ} \mathrm{C}$. In contrast Labyrinthuloides haliotidis grown on pine pollen in seawater failed to develop zoosporoblasts or zoospores and it was suggested that the medium was nutritionally unsuitable to facilitate development of the vegetative stages (Bower 1987b). Enlargement of the vegetative stages of QPX did not occur in FTM or MEM nor did it occur when the cells were removed from the culture media and placed into SAS, although motile stages were released after a few days. 
Preliminary observations of the motile stages of QPX revealed similarities with the zoospore stages of the Thraustochytriales and Labyrinthulales (Kazama 1972a, Perkins 1976). The motile stages of QPX were uninucleate with 2 flagella emerging laterally on either side of the cell (Fig. 12). There appeared to be a thick basal disc at the proximal end of the flagellum and a small amount of electron-dense material in the kinetosome complex although there was no evidence of a distinct electrondense granule as observed in Thraustochytrium spp. and Labyrinthula spp. (Kazama 1972a, Perkins 1976). Bower (1987b) reported that the kinetosome complex of Labyrinthuloides haliotidis did not contain a distinct granule, but possessed only a small amount of electrondense substance in its kinetosome complex. The cell wall of the motile stage of QPX appeared to be loosely multilaminar (Fig. 15). This has also been reported for zoospores of organisms belonging to the Thraustochytriales and Labyrinthulales (Jones \& Alderman 1971. Kazama 1974, Perkins 1976). Another characteristic of these 2 groups is the presence of striated inclusions in the cytoplasm of the motile stages (Kazama 1972a, b, Perkins 1974, 1976, Kumar 1982) but this was not observed in the quahaug parasite. The multiplicity of characteristics shared by QPX and the thraustochytrids and labyrinthulids suggest that this parasite may be related to organisms in these groups but it is difficult to determine with certainty its exact taxonomic affinities. Study of the internal ultrastructure of the motile stage and isolation of the DNA of QPX are currently underway to conclusively identify the taxonomic group to which the parasite belongs.

In conclusion, QPX has been shown to be an important pathogen of hatchery-reared quahaugs and further investigations of the life-cycle, with a view to developing potential avenues of prevention and control, are ongoing. The role of QPX in population dynamics of wild quahaugs also requires further investigation.

Acknowledgements. We thank Mr R. Maloney, Mr P. MacMillan, Atlantic Veterinary College, for his technical assistance and Mr P. Burleigh, Department of Fisheries and Aquaculture (PEI), for his contribution to this project. This project was supported in part by funds awarded to R.J.C. from the Atlantic Fisheries Adjustment Programme for Aquaculture, the Atlantic Canada Opportunities Agency, and the Natural Sciences and Engineering Research Council of Canada and by funds provided to S.E.M. by the Department of Fisheries and Oceans, Canada.

\section{LITERATURE CITED}

Alderman, D. J., Harrison, J. L., Bremer, G. B., Jones, E. B. G. (1974). Taxonomic revisions in the marine biflagellate fungi: the ultrastructural evidence. Mar. Biol. 25: 345-357 Bower, S. M. (1987a). Artificial culture of Labyrinthuloides haliotidis (Protozoa: Labyrinthomorpha), a pathogenic parasite of abalone. Can. J. Zool 65: 2013-2020

Bower, S. M. (1987b). Labyrinthuloides haliotidis n.sp. (Protozoa: Labyrinthomorpha) a pathogenic parasite of small juvenile abalone in a British Columbia mariculture facility. Can. J. Zool. 65: 1996-2007

Bower, S. M., McLean, N., Whitaker, D. J. (1989). Mechanism of infection by Labyrinthuloides haliotidis (Protozoa: Labyrinthomorpha) a parasite of abalone (Haliotis kamtschatkana) (Mollusca: Gastropoda). J. Invertebr. Pathol. 53: $401-409$

Drinnan, R. E., Henderson, E. B. (1963). 1962 mortalities and a possible disease organism in Neguac quahaugs. Annual Report No. B11, Biological Station, St. Andrews, New Brunswick

Hay, R. J. (1989). Histopathology. In: Evans, E. G. V., Richardson, M. D. (eds.) Medical mycology - a practical approach. IRL Press at Oxford University Press, Oxford, p. 261-281

Howard, D. W., Smith, C. S. (1983). Histological techniques for marine bivalve mollusks. NOAA Technical Memorandum NMFS-F/NEC-25. U.S. Dept of Commerce, Washington, DC

Jones, E. B. G., Alderman, D. J. (1971). Althornia crouchii gen. et sp. nov., marine biflagellate fungus. Nova Hedwigia Z. Kryptogamenkd. 21:381-399

Jones, G. M., O'Dor, R. K. (1983). Ultrastructural observations on a thraustochytrid fungus parasitic in the gills of squid (Illex illecebrosus Lesueur). J. Parasitol. 69(5): 903-911

Kazama, F. Y. (1972a). Ultrastructure of Thraustochytrium sp. zoospores. I. Kinetosome. Arch. Mikrobiol. 83: 179-188

Kazama, F. Y (1972b). Ultrastructure of Thraustochytrium sp. zoospores. II. Striated inclusions. J. Ultrastruct. Res. 41 $60-66$

Kazama, F. Y. (1974). Ultrastructure of Thraustochytrium sp. zoospores. IV. External morphology with notes on the zoospores of Schizochytrium sp. Mycologia 66: 272-280

Kumar, S. R. (1982). Fine structure of the thraustochytrid Ulkenia amoeboidea. II. The amoeboid stage and formation of zoospores. Can. J. Bot. 60: 1103-1114

McGladdery, S. E., Cawthorn, R. J., Bradford, B. C. (1991). Perkinsus karlssoni n.sp. (Apicomplexa) in bay scallops Argopecten irradians. Dis. aquat. Org. 10: 127-137

McLean, N., Porter, D. (1982). The yellow-spot disease of Tritonia diomedea Bergh, 1894 (Mollusca: Gastropoda: Nudibranchia): encapsulation of the thraustochytriaceous parasite by host amoebocytes. J. Parasitol. 68(2): $243-252$

Moss, S. T (1985). An ultrastructural study of taxonomically significant characters of the Thraustochytriales and the Labyrinthulales. Bot. J. Linn. Soc. 91: 329-357

Olive, L. S. (1975). Labyrinthulina (labyrinthulas and thraustochytrids). Academic Press, New York

Perkins, F. O. (1973). Observations of thraustochytrid (Phycomycetes) and labyrinthulid (Rhizopodea) ectoplasmic nets on natural and artificial substrates - an electron microscope study. Can. J. Bot. 51: 485-491

Perkins, F. O. (1974). Phylogenetic considerations of the problematic thraustochytreous-labyrinthulid-Dermocystidium complex based on observations of fine structure. Veröff. Inst. Meeresforsch. Bremerhaven, Suppl. 5: 45-63

Perkins, F. O. (1976). Fine structure of lower marine and estuarine fungi. In: Jones, E. B. G. (ed.) Recent advances in marine mycology. Paul Elek (Scientific Books) Ltd, London, p. 279-312

Ray, S. M. (1966). A review of the culture method for detecting Dermocystidium marinum with suggested modifications and precautions. Proc. Natl Shellfish. Ass. 54: 55-69 